Volume 8, No.1.3, 2019

International Journal of Advanced Trends in Computer Science and Engineering

Available Online at http://www.warse.org/IJATCSE/static/pdf/file/ijatcse4581.32019.pdf

https://doi.org/10.30534/ijatcse/2019/4581.32019

\title{
Usability Evaluation of Diabetes Nutriment Diary: A Mobile App for Diabetic Patients
}

\author{
Jasni Ahmad ${ }^{1}$, Subashini Annamalai ${ }^{2}$ \\ ${ }^{1,2}$ School of Multimedia Technology and Communication, \\ Universiti Utara Malaysia, UUM Sintok, Kedah, Malaysia \\ E-mail: jasni@uum.edu.my
}

\begin{abstract}
This paper describes the attempt to investigate the usability of Diabetes Nutriment Diary (DND) mobile application which encourages users who suffer from diabetes to eat healthy by providing nutritious recipes suitable for them. DND derived from the facts that there are many diabetic patients due to imbalance eating habits. DND also provides recipes according to the diabetes' specific symptoms. This paper also elaborates the findings of the DND's usability using the survey method. The survey employed 30 random respondents who are related to diabetes. Three dimensions are evaluated, namely usability, ease of use and user interface satisfaction. The data analysis results show that the DND has simple and pleasant interface, sufficient information and easy to be used and there are more than $90 \%$ acceptance rate towards DND. DND is expected to be a mobile application that can help the diabetics to eat appropriate food range that will help them to maintain their health condition.
\end{abstract}

Key words : Diabetes Nutriment Diary, Mobile App, Diabetics, Diet recipes

\section{INTRODUCTION}

Diabetes is a 21 st century challenge [1]. According to the previous researches, the number of people with diabetes worldwide has more than doubled during the past 20 years [2]. Diabetes is a disease in which the body does not produce or properly use insulin, a hormone that is needed to convert sugar, starches, and other food into energy needed for daily life $^{3}$. Zaini [3] stated that there will be a threefold rise of the disease in Asia and much of these will be seen in China and India (total of 95 million people) by virtue of the massive population of these countries. Nevertheless, the other rapidly developing Asian nations like Singapore, Malaysia, Thailand, and those making up Indochina will also experience the surge. Malaysian should take this problem seriously and take action before it occurs or become worse[4].

According to American Diabetes Association, eating well can improve the patient from suffering diabetes. It will be helpful for them to have a food scheduling for a few days or a week and a write-up of everything they eat [5]. In this era, everyone relies on their smartphone that such easy and convenient. Diabetic checks their daily meal recipe with their smartphone is an idea for this project.

This application calls Diabetes Nutriment Diary (DND) which focuses on the healthy food recipes that should be adopted by the diabetic patients. The patients should know the nutrition and calories of their food intake in order to keep the diabetes at par. DND is a mobile application which encourages the users who suffer from diabetes to eat healthy by providing nutritious recipes suitable for them. DND derived from the facts that there are many diabetic patients due to imbalance eating habits. DND also provides recipes according to the diabetes' specific symptoms. There are two languages provided in the application DND which are English and Bahasa Malaysia. The content of the application DND is the three meal recipes which are breakfast, lunch, and dinner as shown in Figure 1(a). The meals are provided for seven days in a cycle as illustrated in Figure 1(b). This application will also help the patients' family members to prepare a suitable set of foods so that the patients can eat healthy.

The DND application focuses on the usage by the diabetic patients, family members, dieticians, and doctors. With the help of DND, the diabetic patients can know the estimation of calories and nutrition of their daily food intake. By following the food chart provided in DND, the diabetic patients will eat healthier by learning the amount of nutrition and types of recipes to be eaten for every meal for the whole week accurately.

\subsection{The important of DND for Diabetics}

Literatures has suggested that the diabetic patients should eat and avoid certain food to keep their sugar level in control. Taking this into consideration, the researchers believe that there should be simple, portable application such as DND that acts like a diary or recipe book for them to refer. Even though there are a few mobile applications that attempt to help the diabetic patients, the existing diabetes applications are too complicated even for someone who with technology background [5-7]. According to Deputy Health Minister of Malaysia, Datuk Seri Dr. Hilmi Yahaya, more young people are suffering from diabetes due to the spike in the rate of obesity, which is related to their imbalanced eating habits [8].

The ingredients and recipes of DND mobile application as illustrated in Figure 1(b), helps the users, especially the 
diabetic patients to prepare healthier dishes which will result in healthier eating practices.

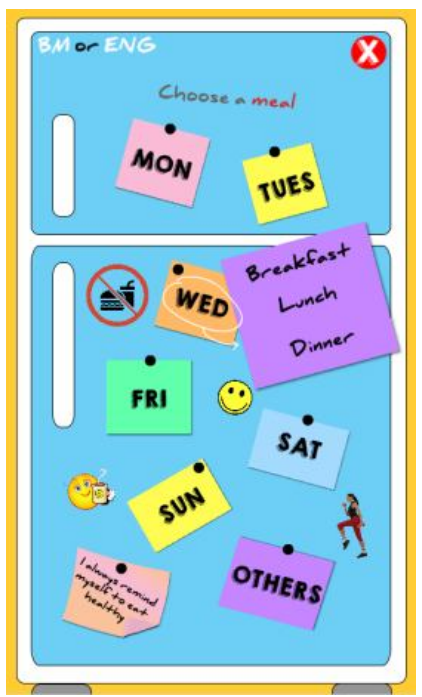

(a)

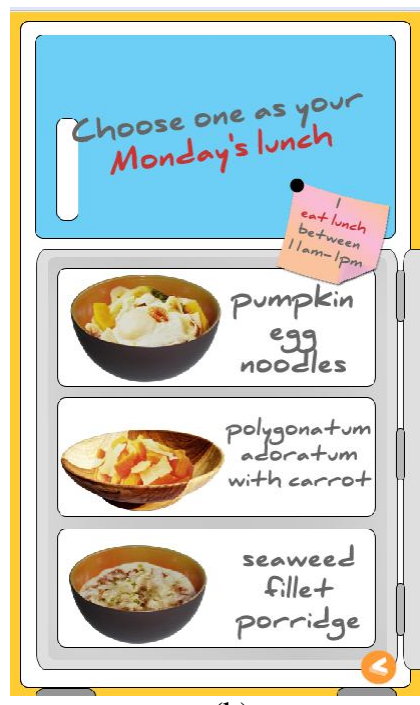

(b)
Figure 1: Meal and example recipes of DND

In addition, DND also provides specific meals recipes for users with different symptoms of diabetes as illustrated in Figure 2. Each symptom has three meals, namely breakfast, lunch, and dinner, and each meal is provided with three different recipes. There are also suggestions for users for serving the meals (breakfast, lunch and dinner) with some side dishes or beverages. In addition, DND provides some diabetes related information such as the difference between Type 1 diabetes and Type 2 diabetes and how to prevent or control the diabetes disease by suggesting the amount of foods that the diabetic patients should eat daily. When the users would like to exit the application, they can click on the exit buttons that will show a confirmation question as illustrated in Figure 3. If users choose to "Stay with DND", the mobile application will back to the main interface and if the users choose to eat "Alone", then the application will exit from the DND app.

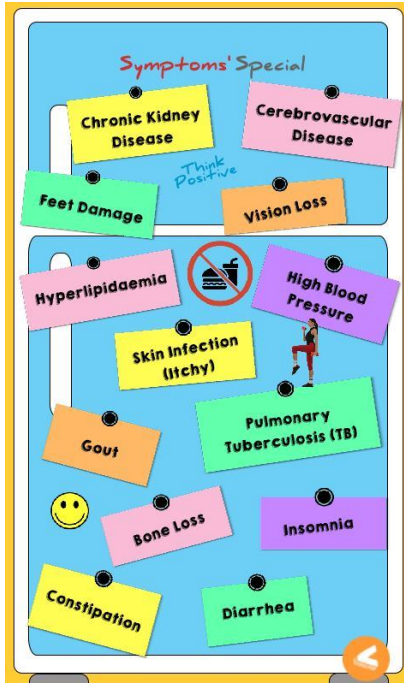

(a)

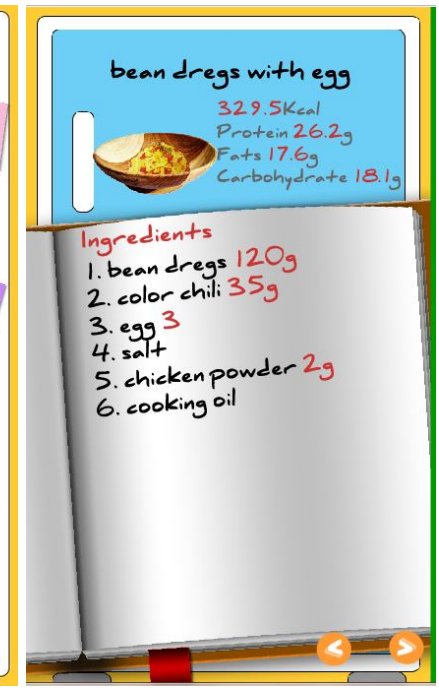

(b)
Figure 2: Symptoms in DND and the recipes

\subsection{Analysis of Diabetes' android mobile application}

There are 15 existing mobile applications that attempts to help the diabetic patients on food choice and all of these applications can be downloaded free and available for the Android phone users only. However, most of these existing applications is not user-friendly and do not have complete features. The researchers have conducted a comparative analysis of the existing applications with DND and the result is described in Table 1. The comparative analysis included features such as free download, device dependency, recipes, food images, calories, advertisements, searching capability, sharing function, nutrition, beverages, diabetes information, help-tutorial, amount of meals (three meals per day), duration of the recipes (one week etc.), and languages.

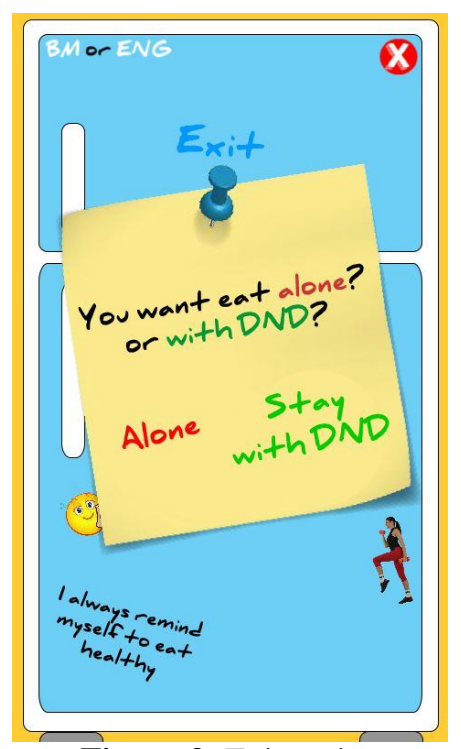

Figure 3: Exit option

Table 1: Comparison of existing applications' features with DND

\begin{tabular}{|c|c|c|c|c|c|c|c|c|c|c|c|c|c|c|c|}
\hline & F1 & F2 & F3 & F4 & F5 & F6 & F7 & F8 & F9 & F10 & F11 & F12 & F13 & F14 & F15 \\
\hline A1 & 7 & 7 & 1 & 7 & 1 & $/$ & 7 & & 7 & $1 /$ & 7 & & & & \\
\hline $\mathrm{A} 2$ & 7 & 7 & 7 & 7 & $/$ & $/$ & 7 & & 7 & $/ 1$ & & & & & \\
\hline $\mathrm{A} \mathbf{3}$ & 7 & $/ 1$ & $/ 1$ & 7 & 7 & & 7 & $/ 1$ & $7 /$ & $/ 1$ & & & & & \\
\hline A4 & 1 & 1 & 1 & 1 & 1 & & 1 & & 1 & & & 1 & & & \\
\hline A5 & 7 & 7 & I & 1 & & 1 & I & & & 1 & & I & & & \\
\hline A6 & 1 & 1 & 1 & & 1 & 1 & & 1 & & & & & 1 & 1 & \\
\hline A? & 1 & 1 & 1 & 1 & 1 & 1 & & 1 & 1 & & & & & & \\
\hline A8 & 1 & 7 & 1 & 1 & 1 & 1 & 7 & 1 & 1 & & & & & & \\
\hline A9 & 1 & $1 /$ & 1 & 1 & 1 & 1 & & 1 & $1 /$ & & & & & & \\
\hline A10 & 1 & 7 & 1 & 1 & 1 & & & 1 & & & & & 1 & & \\
\hline Al1 & 7 & 7 & 1 & 1 & & 1 & 1 & 1 & & & & & & & \\
\hline A12 & 1 & 1 & 1 & 1 & & & 1 & & & & & & & & 1 \\
\hline A13 & 1 & 1 & 1 & 1 & & & & 1 & & & & & & & \\
\hline A14 & 1 & 7 & & & 1 & & & & & 1 & 1 & & & & \\
\hline A15 & 1 & 1 & 7 & 7 & & & & & & & & & & & \\
\hline SUM & 15 & 15 & 14 & 13 & 10 & 8 & 8 & 8 & 7 & 5 & 2 & 2 & 2 & 1 & 1 \\
\hline
\end{tabular}

\section{Application Name: Features:}

A1- Diabetes Recipe Apps F1- Free Download

A2- Diabetes Recipes: Healthy Food F2- For Android Phone A3- Diabetes Food Recipes: Free! F3- Recipes A4- Recipes for Diabetes F4- Pictures A5- Diabetes Recipe Diabetes RecipeF5- Calories A6- Diabetes Diet Chart F6- Advertisements A7- Diabetes Diet Food Recipes F7- Searching capacity A8- Diabetes Diet Free F8- Sharing Function 
A9- Diabetes Recipes F9- Nutrition

A10- Diabetes Weight Loss Diet F10- Beverage

A11- Diabetes Recipes Free F11- Diabetes Information

A12-Diabetes Recipes Free F12- Help-tutorial

A13- Diabetes Cookbook F13- Meals per Day

A14- Diabetes and Fast Food F14- Meals for One Week

A15- Delicious Diabetes Recipes F15- Language

According to the comparative analysis, most of the existing applications do not focus on the important features such as meals per day, meals per week and diabetes information. Although Diabetes Recipe Apps (A1) provides most of the features, it is not user friendly and it is written and illustrated in English language. Therefore, it does not cater for the Malaysian whose mother tongue is Bahasa Malaysia. DND is designed to cater the need of Malaysian and also International users as it provides bilingual features. Not only that, DND app provides recipes that are suitable for Malaysian users. Another application, namely the Diabetes Diet Chart (A6) does provide both fixed three meals a day and fixed meals for a week, however it does not provide the nutrition information. This will hinder the users from knowing the benefits of the meal and the reason why the particular meal will help to improve health. This feature is provided in DND, so that the users can eat healthier by knowing the nutrition benefits of the particular recipe they chose to eat. Not only that, DND also provided one of the features that does not exist in any diabetes' mobile applications which is the recommended recipes of three meal times for the specific 13 symptoms of diabetic patients.

\section{PROTOTYPING DND: A VIABLE SOLUTION}

A prototype of the DND mobile application was developed to encourage users who suffer from diabetes to eat healthy by providing nutritious recipes suitable for them. This prototype was designed and developed by using the ADDIE Model (Analyse, Design, Develop, Implement, and Evaluate). This DND prototype embeds text, video, sounds and background music, to attract the users and motivate them to use the application. The layout and navigational behaviour of the application was designed using the interaction design theory (IxD).

\section{METHOD}

The purpose of conducting the usability evaluation of the prototype of the DND mobile application is to get the feedback from different range of 30 users who are related to the diabetes such as the patients, family, doctors and dietician. Three dimensions are evaluated, namely functionality, ease of use and user interface satisfaction. A survey was used as the evaluation method. This is to get the direct feedback from the actual users [9-11] and this feedback is used to revise and improve the user interface and functionality of the DND mobile application.

\subsection{Sample selection}

This survey employed 30 respondents from different states in Malaysia. The respondents include diabetes patients, family members, dieticians and doctors. These respondents are chosen randomly and the reason for choosing a small sample size is because the usability evaluation was done on a prototype that may have certain drawbacks that need to be looked into. All the respondents chosen in the context that they might need the DND application in their daily life or they could recommend the DND to people that need it.

\subsection{Procedures}

There are 13 questions on the survey questionnaire that need to be answered, focusing on functionality, ease of use and user interface satisfaction. The respondents will experience the DND mobile application for 30 minutes. Prior to the intervention, the users were briefed on the details of DND and how to use it. After the intervention, the respondents were given the survey questionnaire that has been validated by expert's earlier $[12,13]$. The data from the questionnaire was analysed using descriptive statistics, and is taken into consideration to improve DND in future.

\section{FINDINGS}

The data collected from the survey are analysed using descriptive statistic. These data represent the finding of the usability evaluation of the DND mobile application. This evaluation testes the DND's 'user-friendliness' and how the users interact with it. Among the aspects that are evaluated are functionality, ease of use and user interface satisfaction of the DND mobile application. Usability testing is testing for 'user-friendliness'. Way to evaluate and measure how users interact with a software product or a website.

\subsection{Demographic}

The respondents for the DND usability survey are diabetic patients, family members, dieticians and doctors. 13 people $(43 \%)$ out of the 30 respondents are diabetic patients, 10 are the family members, 5 respondents are dieticians and the rest (7\%) are doctors. The respondents' age ranges from 27 to 60 years old.

\subsection{Functionality}

Table 2 describes the descriptive analysis of the functionality aspect of the usability evaluation of DND.

Table 2: Functionality of DND

\begin{tabular}{llc}
\hline Components & Scale & $\begin{array}{l}\text { No. of } \\
\text { Respondents }\end{array}$ \\
\hline \multirow{3}{*}{ Interactivity } & Very good & 20 \\
& Good & 8 \\
& Neutral & 2 \\
\hline \multirow{2}{*}{ Navigation } & Very good & 14 \\
& Good & 13 \\
& Neutral & 3 \\
Information & Very good & 11 \\
Organization & Good & 18 \\
& Neutral & 1 \\
\hline
\end{tabular}


The overall reaction of the functionality of DND is reported as good. The functionality aspect of DND is divided into three components; interactivity, navigation and information organization. 20 respondents stated that the interactivity of the mobile application as very good, whereas 8 stated as good and 2 as neutral. As for the navigational aspect, 14 of the 30 respondents asserted that they can navigate through the application freely and it is straight forward. It is stated as simple, visible and consistent. 13 of them stated that DND has good navigation and 3 respondents was feeling neural. In addition, almost all the respondents confirm that the information and its organization is sufficient and will be very helpful to the diabetic patients.

\subsection{Ease of use}

The respondents also evaluated the ease of use aspects of the DND mobile application. Table 3 portrays the descriptive analysis of the ease of use aspect of the DND mobile application.

Table 3: Ease of use of DND

\begin{tabular}{llc}
\hline Components & Scale & $\begin{array}{l}\text { No. of } \\
\text { Respondents }\end{array}$ \\
\hline \multirow{4}{*}{ Language } & Very good & 3 \\
& Good & 14 \\
& Neutral & 10 \\
& Bad & 3 \\
\hline \multirow{3}{*}{ Learnability } & Very good & 10 \\
& Good & 16 \\
& Neutral & 4 \\
\hline Usefulness & Very good & 26 \\
& Good & 3 \\
& Neutral & 1 \\
\hline
\end{tabular}

The ease of use aspects of DND has some issues pertaining the language used. DND is bilingual, which the users can choose to use Bahasa Malaysia or English. However, 3 respondents stated that they prefer the app to be in their native language, to make them understand the content better. Therefore, they have stated the language used in the application as bad. But the rest of the respondents stated that the language used in the application is easy to be understood. 17 of them agreed that they can understand both languages as DND uses simple language to interact with the users. 10 of the respondents expressed the neutral feelings.

As for the learnability aspects, 26 of the respondents claim that the DND mobile application is easy to be learned without any help. This is because the layout and the control are consistent and does what it supposed to do. The usefulness aspect concerns the degree to which the DND mobile application enables a user to achieve his or her goals, and it is an assessment of the user's willingness to use it. For this, 26 of the 30 respondents agree that the DND mobile application will be very useful for the diabetic patients as it will encourage them to eat healthy by providing nutritious recipes suitable for them.

\subsection{Interface satisfaction}

Table 4 illustrates the descriptive analysis of the interface satisfaction aspects of the DND mobile application.

Table 4: Interface satisfaction of DND

\begin{tabular}{llc}
\hline Components & Scale & $\begin{array}{l}\text { No. of } \\
\text { Respondents }\end{array}$ \\
\hline \multirow{2}{*}{ Layout } & Very suitable & 16 \\
& Suitable & 14 \\
\hline \multirow{3}{*}{ Colour } & Very suitable & 20 \\
& Suitable & 8 \\
& Neutral & 2 \\
\hline \multirow{3}{*}{ Font } & Very suitable & 26 \\
& Suitable & 3 \\
\multirow{2}{*}{ Control } & Neutral & 1 \\
& Very suitable & 24 \\
& Suitable & 6 \\
\hline
\end{tabular}

The interface satisfaction aspect is separated into four components; layout, colour, font and control (buttons). For the layout component, the respondents are happy with the layout structure of DND. The respondent stated that there is a consistency of the design layout, and the different sections of the app are coherent in design. As for the colour component, 28 of the respondents describes that DND has a colour scheme and it helps users see and interpret your app's content, interact with the correct elements, and understand actions. However, 2 of them feel neutral with the colours used in the DND mobile application. Meanwhile, 29 of the respondents stated that the font used in the mobile application is suitable, and used the proper typographical elements.

Furthermore, all of the respondents feel that the usages of the control elements in the mobile application are appropriate. This is because DND uses touch controls that make the interaction with the app feels easy. Not only that, it uses the appropriate hit target size and colour contrast to avoid inaccuracy of navigation.

\section{DISCUSSIONS AND CONCLUSIONS}

The DND mobile application will be a good start up for the technology-based recipe diary of Malaysian diabetic patients. The finding of the usability evaluation indicated that the DND mobile application has simple and pleasant interface, sufficient information and easy to be used. DND is also visually appealing, and this attracted the respondents to continue using it. The overall reaction of users indicated that 93.3\% of respondents agree that the recipes provided in DND are good and will encourage them to eat healthier. This is because DND recommends a healthier range of foods that contain high nutrition to help diabetic patients to maintain their health condition. 
The study proves that DND has positive attributes that could contribute to healthier eating habits and in the long run, improve the diabetic patients' health condition. The developed DND prototype is found to be satisfying and usable, as it fulfils the users' expectation of the three dimensions which are usability, ease of use and user interface satisfaction.

The feedback and comments that are given by the respondents who represent the target users will be implemented in future development of DND to make it a better diabetes mobile application compare to the other existing diabetes mobile applications in the market.

\section{ACKNOWLEDGEMENT}

This work is financially supported by the Self Fund Research Grant under the Universiti Utara Malaysia. Special thanks to DND development team, Lim Hui Teng and Erene Mong.

\section{REFERENCES}

[1] National Diabetes Statistics Report, available online: https://www.cdc.gov/diabetes/pdfs/data/statistics/nation al-diabetes-statistics-report.pdf, last visit: 13.11.2017.

[2] Zimmet PZ, Magliano DJ, Herman WH, Shaw JE. Diabetes \& endocrinology, available online: http://www.thelancet.com/ journals/landia/article/PIIS2213-8587(13)701 12-8/abstract, last visit: 1.12.2013.

[3] Diabetes Malaysia, Healthy eating, available online: http://www. diabetes. org.my/article.php?aid=582, last visit: 15.06.2016

[4] Zaini A, Where is Malaysia in the midst of the Asian epidemic of diabetes mellitus?. Ireland: Elsevier Inc, available online:

http://www.diabetesresearchclinicalpractice.com/article /S0168-8227(00) 00175-3/abstract, 2000.

[5] American Diabetes Association, What is Prediabetes, available online:

http://clinical.diabetesjournals.org/content/diaclin/31/2/ 95. full.pdf, last visit: 17.06.2015

[6] Petrow $S$, The app revolution for diabetes, available online:

https://www.washingtonpost.com/national/health-scien ce/the-app-revolution-for-diabetics/2015/06/15/6810d1 3a-0481-11e5-8bda-c7b4e9a8 f7ac_story.html, last visit: 15.06.2016

[7] Billa, 5 Detailed Diabetic Diet Apps for Android, available online: http://joyofandroid.com/best-diabetic-diet-apps-android /, last visit: 15.01.2017

[8] Malaymail online, Diabetes among young on the rise, Deputy Health Minister, available online: http://www.themalaymailonline. com/malaysia/article/diabetes-among-young-on-the-ris e-says-deputy-health-minister, last visit: 13.11.2017

[9] Wyse SE, The 4 Main Reasons to Conduct Surveys, available online: https://www.snapsurveys.com/blog/4-main-reasons-con duct -surveys/, last visit: 29.06.2017

[10] McKee S, Why Are You Doing a Survey? The Importance of Goals, available online: https://www.surveygizmo.

com/survey-blog/importance-of-survey-goals/, last visit: 05.01.2017

[11] Teller S, Sample size: How many people should take the survey?, available online: https://ondeviceresearch. $\mathrm{com} / \mathrm{blog} / \mathrm{sample}$-size-people-participate-take-survey, last visit: 29.01.2017

[12] Durbin CG. (2004), Effective use of tables and figures in abstracts, presentations, and papers, Respiratory care 49(10), 1233-1237.

[13] Petrow $S$, The app revolution for diabetes, available online:

https://www.washingtonpost.com/national/health-scien ce/the-app-revolution-for-diabetics/2015/06/15/6810d1 3a-0481-11e5-8bda-c7b4e9a8f7ac_story.html, June 15, 2015. 